\title{
Prescription pattern in the management of chronic obstructive pulmonary disease patients in a tertiary hospital: an observational study
}

\author{
Poonam Salwan ${ }^{1 *}$, Juhi Singla², Shalini Salwan ${ }^{3}$
}

\begin{abstract}
${ }^{1}$ Department of Pharmacology, Shree Guru Gobind Singh Tricentenary, Medical College, Gurugram, Haryana, India ${ }^{2}$ Department of pharmacology, Alfalah School of Medical Science and Research Institute, Faridabad, Haryana, India ${ }^{3}$ Department of pharmacology, Punjab Institute of Medical Sciences, Jalandhar, Punjab, India
\end{abstract}

Received: 10 August 2020

Accepted: 09 September 2020

*Correspondence:

Dr. Poonam Salwan,

Email: salwanpoonam@yahoo.in

Copyright: (C) the author(s), publisher and licensee Medip Academy. This is an open-access article distributed under the terms of the Creative Commons Attribution Non-Commercial License, which permits unrestricted non-commercial use, distribution, and reproduction in any medium, provided the original work is properly cited.

\begin{abstract}
Background: Drug utilization studies promote rational use of drugs and help to decrease the adverse drug reactions. Such studies are powerful tools to evaluate the role of drugs in the society. The present study is aimed to analyse and evaluate the trends and patterns of prescribing drugs among chronic obstructive pulmonary disease (COPD) patients. Methods: A prospective observational study was conducted in 112 patients of COPD admitted in the general and pulmonary medicine departments over a period of 1-year in SGT Medical College, Hospital and Research Institute, SGT University, Gurugram. Patients, who satisfied the inclusion criteria, were enrolled in the study after taking informed consent. Data was collected by using the specially designed data entry form and put in tabulated form. The results were expressed as percentages. The following information was collected for each patient: social demographics, smoking history, prescribed COPD treatments. Health related quality of life indices were obtained using validated questionnaires.

Results: Out of the 112-study population, male patients were more in number $(76.36 \%)$. The majority of the patients were from the age group of 61-70 years (47.2\%) with $56.36 \%$ patients showing severe rating (poor score) of quality of life on COPD assessment test. Smoking was found to be more prominent in the study population (71.42\%). Inhaled corticosteroids $(67.85 \%)$ were most prescribed class of drugs in the management of COPD followed by systemic bronchodilators $(64.28 \%)$. The most commonly prescribed bronchodilator was systemic methylxanthine (deriphylline$64.28 \%$ ) followed by systemic $\beta 2$ agonist (Terbutaline-62.5\%). Inhaled corticosteroids $(67.85 \%)$ were prescribed more often than systemic corticosteroids. Among antimicrobials, the most commonly prescribed drug was Amoxicillin-clavulanic combination $(35.71 \%)$ and ceftriaxone $(35.71 \%)$. Considering the drugs prescribed for comorbid conditions, proton- pump inhibitors (73.21\%) topped the list followed by antihistaminic (37.5\%) for allergic conditions.

Conclusions: The study concludes that symptomatic treatment was given to COPD patients in the hospital. The prescribing pattern was found to be in concordance with the current global Initiative for chronic obstructive lung disease (GOLD) guidelines in the management of COPD patients.
\end{abstract}

Keywords: Bronchodilators, Drug utilization, Prescription pattern 


\section{INTRODUCTION}

Globally and in India, chronic respiratory diseases are a common cause of disease burden. About 100 million people are suffering from obstructive lung diseases. ${ }^{1}$ WHO defines chronic obstructive pulmonary disease (COPD) as a lung disease characterized by a persistent blockage of airflow from the lungs. It is an underdiagnosed, life-threatening lung disease that interferes with normal breathing and is not fully reversible. ${ }^{2}$ Affecting $10 \%$ of the population over the age of 40 years the burden of chronic obstructive pulmonary disease (COPD) has reached epidemic proportions. ${ }^{3}$ As it is a chronic and highly prevalent disease, it requires frequent physician visits and numerous hospitalizations because of acute exacerbations and requires long term therapy. Performing a correct diagnosis in COPD is important as appropriate treatment reduce the symptoms as well as decreases the number of acute exacerbations thus improving the quality of health, ability to exercise and life expectancy. ${ }^{4}$

The burden of COPD is likely to increase due to associated risk factors and aging of the population, with smoking being the primary risk factor. COPD has been projected as the fourth leading cause of death in 2030, accounting for $7.8 \%$ of total deaths. There are wide variations seen in the prevalence of COPD across countries, being higher in patients with a smoking history, those over 40 years of age, and in men than in women..$^{5-8}$ The national health and nutrition examination survey (NHANES) data suggest that $7 \%$ of the adult population in the USA have low lung function which is closely related to cigarette consumption and increasing age. Further, it suggests that nearly $70 \%$ of adults with low lung function never had a diagnosis of obstructive lung disease which points towards work-related exposures to be an important contributor to the overall burden of COPD. ${ }^{9}$ Among working-age patients, COPD is the $11^{\text {th }}$ leading cause of work productivity loss due to compromised quality of life. ${ }^{10}$

Drug utilization studies can contribute to designing of national health policies to promote the availability of safe and effective medicines, while also reducing costly overmedication. ${ }^{11}$ Prescription pattern monitoring studies are basically drug utilization studies targeting prescription and administration of drugs. They promote the appropriate use of monitored drugs as also reducing their abuse or misuse. Inappropriate prescribing patterns lead to failure in therapeutic effectiveness, increased exacerbation, decreased quality of life along with higher costs. ${ }^{12}$

The Objective of this study is to facilitate rational use of medications and promote sensible use of available resources. This study serves to spotlight the current prescribing trends in patients with COPD visiting our hospital.

\section{METHODS}

This was a prospective observational study, conducted in the chest and TB and general medicine ward of SGT Medical College and Hospital and Research Institute, Gurugram. The study was conducted for a period of 1-year from September 2017 to September 2018 after taking approval from the institutional ethics committee and institutional thesis committee. The Study was registered in clinical trial registry of India wide letter no. CTRI/2017/09/009901.

\section{Inclusion Criteria}

A total 112 COPD patients of either sex with or without co-morbidity and age between 40-90 years, admitted to chest and TB and general medicine department during the study period were enrolled for the study.

\section{Exclusion Criteria}

Patients who refused to participate, children, pregnant and lactating women were excluded from the study.

Patients, who satisfied the inclusion criteria, were enrolled in the study after taking informed consent. Data was collected by using the specially designed data entry form. The following information was collected for each patient: social demographics, smoking history, prescribed COPD treatments. Health related quality of life indices were obtained using validated questionnaires. This data was analysed by using microsoft excel and results were presented as percentages.

\section{RESULTS}

In this study, 112 subjects were included, among them, 86 (76.78\%) were males and $26(23.21 \%)$ were females. The mean age of patients was 66.9 years (Table 1) age distribution of study population $(\mathrm{n}=112)$.

Table 1: Age distribution of study population $(\mathrm{n}=112)$.

\begin{tabular}{|l|l|}
\hline Age (in years) & No. of patients (\%) \\
\hline $\mathbf{4 0 - 5 0}$ & $7(12.7)$ \\
\hline $\mathbf{5 1 - 6 0}$ & $7(12.7)$ \\
\hline $\mathbf{6 1 - 7 0}$ & $26(47.2)$ \\
\hline $\mathbf{7 1 - 8 0}$ & $9(16.36)$ \\
\hline $\mathbf{8 1 - 9 0}$ & $6(10.9)$ \\
\hline
\end{tabular}

According to our observation, 80 (71.42\%) patients were smokers, while $5(8.92 \%)$ were non-smokers, and 20 (17.85\%) were ex-smokers and $82(73.21 \%)$ were passive smokers (Table 2). Regarding quality of life scores, majority of the selected patients $(56.36 \%)$ fall in $21-30$ range (Figure 1). 


\section{Drug use in COPD patients}

In total 112 patients, Budesonide was maximum prescribed drug $n=76(67.85 \%)$ followed by theophylline $\mathrm{n}=72(64.28 \%)$, terbutaline $\mathrm{n}=70(62.5 \%)$, ambroxyl $\mathrm{n}=72$ (64.28\%), salbutamol/levosalbutamol, $\mathrm{n}=66 \quad(58.9 \%)$, ipratropium $n=48(42.8 \%)$, levo-cetirizine $n=42(37.5 \%)$, montelukast $n=36(32.14 \%)$, formetrol $n=30 \quad(26.78 \%)$ hydrocortisone $n=28(25 \%)$, tiotropium $n=4(3.57 \%)$.

Table 1: Characteristics of study population $(n=112)$.

\begin{tabular}{|ll|}
\hline Variables & Mean (SD) or percentage \\
\hline Males & 76.36 \\
\hline Females & 23.63 \\
\hline Age (in years) & 66.9 \\
\hline Active smokers & 71.42 \\
\hline Ex-smokers & 17.85 \\
\hline Passive smokers & 73.21 \\
\hline Quality of life scores & \\
\hline $10-20$ & 12.72 \\
\hline $21-30$ & 56.36 \\
\hline $31-40$ & 30.90 \\
\hline
\end{tabular}

QoL scores of COPD patients

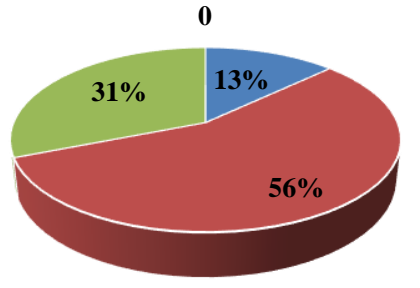

- 10 to $20 \quad-21$ to $30 \quad-31$ to 40

Figure 1: QoL scores of COPD patients.

Table 3: Drug utilization in COPD patients.

\begin{tabular}{|l|l|}
\hline Drug category & $\begin{array}{l}\text { No. of } \\
\text { patients }(\%)\end{array}$ \\
\hline Antibiotics & $98(87.5)$ \\
\hline Short acting beta-2 agonist & $66(58.9)$ \\
\hline Anticholinergic agent & $52(46.42)$ \\
\hline Inhaled corticosteroids & $76(67.85)$ \\
\hline Methylxanthines & $74(66.07)$ \\
\hline Systemic corticosteroids & $28(25)$ \\
\hline Anti-histaminics & $42(37.5)$ \\
\hline Leucotriene receptor antagonist & $36(32.1)$ \\
\hline Long acting beta-2 agonist & $30(26.78)$ \\
\hline Ambroxyl & $72(64.28)$ \\
\hline
\end{tabular}

Under evaluation of different classes of drugs used in the therapy we found that Corticosteroids, both inhaled and systemic, $104(92.85 \%)$ were frequently used followed by antibiotics 98 (87.5\%), methylxanthines 74 (66.07\%), anticholinergics $52(46.42 \%)$, antihistaminic 42 (37.5\%), leukotriene receptor antagonist were used only in 36 $(32.1 \%$ ) patients (Table 3 ) and (Figure 2).

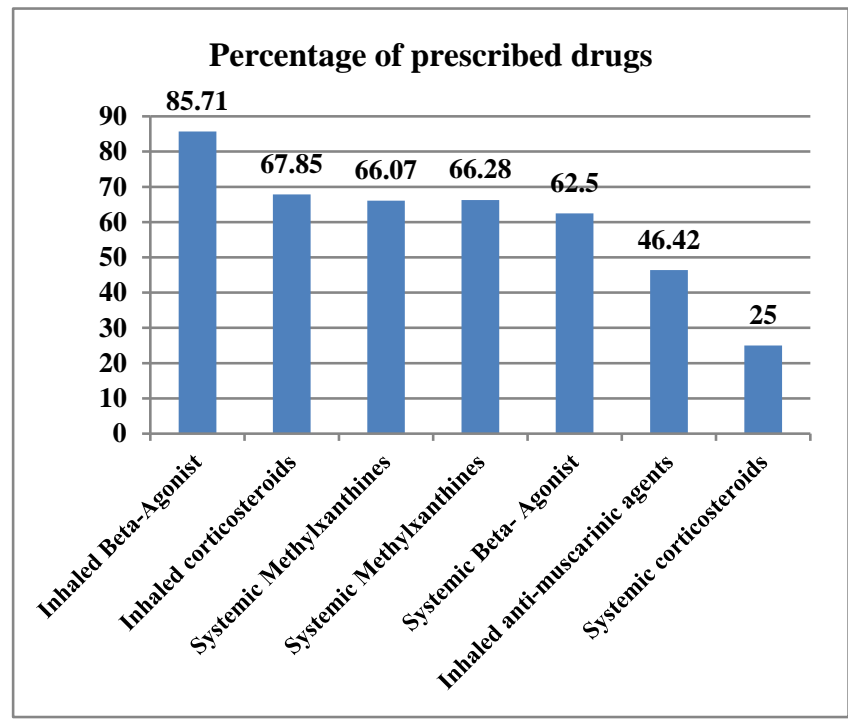

Figure 2: Drug utilization pattern in COPD patients.

Considering the drugs for the management of co-existing conditions, anti-hypertensives were prescribed to 24 $(14.04 \%)$ subjects, anti-platelets to $28(2.29 \%)$, diuretics to $8(26.07 \%)$, nitrates to $16(7.45 \%)$, anti-arrythmics and alpha-blockers each to $4(3.57 \%)$, hypolipidemics to 2 $(1.78 \%)$ patients. With respect to drugs acting on GIT, PPI'S were most frequently prescribed to $82(73.21 \%)$ patients, antacids to $6(5.35 \%)$, anti-emetics to $4(3.57 \%)$, histamine-2 blockers and probiotics to $2(1.78 \%)$ patients. Other drugs included; NSAIDS to 28 (25\%), opiate analgesics to $2(1.78 \%)$, multi-vitamin to $90(80.35 \%)$, anti-depressants to $36(32.14 \%), 12(10.71 \%)$ patients were on DOTS therapy. The results are given in (Figure 3).

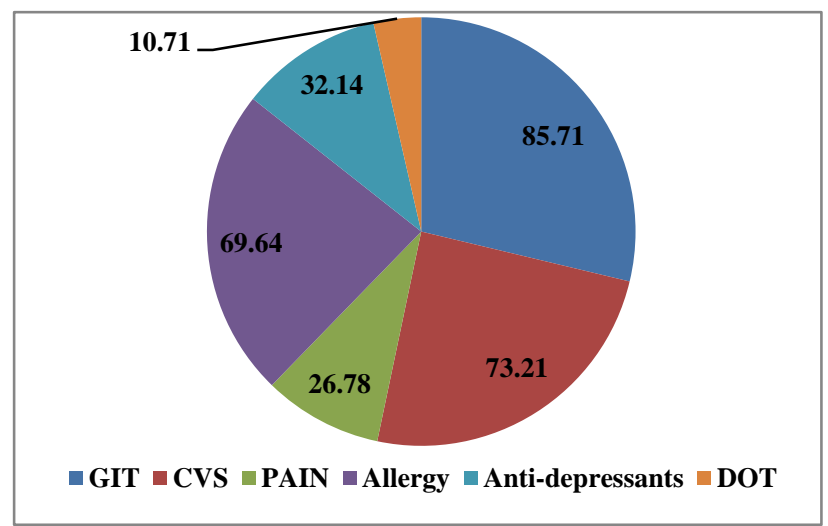

Figure 3: Distribution of various co-morbid conditions.

Most commonly prescribed antibiotic was amoxicillinclavulanic acid combination and ceftriaxone $40(35.71 \%)$ followed by azithromycin and levofloxacin $20(17.85 \%)$, 
cefpodoxime $10(8.9 \%)$, amikacin $8(7.14 \%)$, cefixime 6 $(5.35 \%)$, metronidazole $4(3.57 \%)$, clindamycin, gentamicin and doxycycline to $2(1.78 \%)$ patients (Table 4).

\section{Table 4: Drug utilization of antibiotics in} COPD patients.

\begin{tabular}{|lll|}
\hline $\begin{array}{l}\text { Type of } \\
\text { antibiotic }\end{array}$ & $\begin{array}{l}\text { Number of times } \\
\text { prescribed }\end{array}$ & Percentage \\
\hline $\begin{array}{l}\text { Amoxycillin- } \\
\text { clavulanic acid }\end{array}$ & 40 & 35.71 \\
\hline Ceftriaxone & 40 & 35.71 \\
\hline Azithromycin & 20 & 17.85 \\
\hline Levofloxacin & 20 & 17.85 \\
\hline Cefpodoxime & 10 & 8.9 \\
\hline Amikacin & 8 & 7.14 \\
\hline Cefixime & 6 & 5.35 \\
\hline Metronidazole & 4 & 3.57 \\
\hline Clindamycin & 2 & 1.78 \\
\hline Doxocycline & 2 & 1.78 \\
\hline Gentamicin & 2 & 1.78 \\
\hline
\end{tabular}

\section{DISCUSSION}

Based on the data of the present study, COPD was found to be more common among males rather than females. It might be due to the fact that most of the men smoke and it seems to be an important contributing factor of COPD. People of age group 61-70 years were found to be more affected. The age distribution supported the evidence of the previous studies that only those above 40 years of age were admitted during the period of the study. Regarding the sex wise distribution, majority of the patients were males who accounted for $76.36 \%$. The females accounted for around $23.63 \%$. This only confirmed the finding of the previous study conducted that males accounted for the majority of the disease burden. ${ }^{13}$

Most of the patients in the present study had co-morbid conditions $(n=86 ; 76.78 \%)$. The most commonly observed co-morbid conditions were related to GIT followed by cardiovascular system. Many patients were on Antidepressants $(32.14 \%)$. About $10.71 \%$ patients were on DOT (directly observed therapy) for tuberculosis. These findings are almost similar to the result of previous study in which $69.8 \%$ patients had co-morbid conditions. ${ }^{13}$

In our study, all the patients were receiving combination therapy. ${ }^{14}$ This is in accordance with the previous studies and this prescribing trend may be attributed to achieve the goals of COPD therapy including minimization of symptoms, preventing recurrent exacerbations, reducing the need for hospitalizations and maintaining the pulmonary function.

Out of the patients receiving methylxanthines, $64.28 \%$ were receiving hydroxyethyl theophylline (dyphylline) and the remaining aminophylline. As per the GOLD (global initiative for obstructive lung disease) criteria and reviews of cochrane, patient presenting with COPD is to be initially managed with $\beta$-agonists followed by anticholinergics. ${ }^{15,16,17,18}$ Due to the alleged adverse effects associated with methylxanthines, their role remains controversial. In this study, the use of methylxanthines was found to be high and the usage of anticholinergics was on the lower side. This might be due to easy availability of the methylxanthines and relative non availability of anticholinergics in the hospital of study.

Majority of the patients were receiving either oral or inhalational $\beta$-agonists. Inhalational short-acting beta- 2 agonists salbutamol and levosalbutamol (58.9\%) were prescribed in accordance with the GOLD guidelines, which quickly relieves the symptoms of patients. Other long acting beta-agonists like formetrol (26.78\%) were also prescribed. Systemic beta 2 agonists terbutaline $(62.5 \%)$ was also prescribed. Parenteral steroids were used in $25 \%$ of the patients which constituted hydrocortisone. Steroid inhalers were used in $67.85 \%$ of patients with all of them receiving budesonide. These are in accordance with the GOLD guidelines, as on one hand, steroids decrease the recovery time and hospital stay and at the same time improve lung function. However, another study showed more use of parenteral steroids than inhalational ones. ${ }^{19}$

Anticholinergics were used in $46.42 \%$ of patients in which $92 \%$ were on ipratropium. ${ }^{14}$ Their use is supported by the previous study in which addition of tiotropium resulted in a significant reduction in exacerbation frequency. ${ }^{20}$ However, in our study, short-acting antimuscarinic agent ipratropium was used more frequently than the long-acting tiotropium.

Antibiotics were used in $87.5 \%$ patients. According to the antibiotic groups, most of the patients came under group B $(62.5 \%)$, followed by group A $(17.5 \%)$ and group C $(8.5 \%)$ where group A indicates mild exacerbation: No risk factors for poor outcome, group B indicates moderate exacerbation with risk factor (s) for poor outcome and group $\mathrm{C}$ indicates severe exacerbation with risk factors for pseudomonas aeruginosa infection. ${ }^{19}$ This finding is in accordance with the previous studies, which revealed $86.7 \%$ use of antibiotics. However, some other studies revealed $52 \%$ and $99 \%$ use of antibiotics. ${ }^{14,21}$ It might be due to difference in prevalence of infections among the patients admitted with COPD in different demographic areas.

\section{CONCLUSION}

Through this study on COPD patients, it was found that male patients outnumbered female patients. The majority of the drugs prescribed were in accordance with the global initiative for chronic obstructive lung disease (GOLD) guidelines. In this study, the major risk factor of the disease was found to be smoking, so patients should be 
counselled to quit smoking and use of masks can be promoted to prevent inhaling of noxious particles. In this study, no patient had undergone vaccination, so it should be made available to the patients as per global initiative for chronic obstructive lung disease recommendations. Influenza vaccination should be considered for all patients of COPD and Pneumococcal vaccination recommended for patients $\geq 65$ years.

\section{Funding: No funding sources}

Conflict of interest: None declared

Ethical approval: The study was approved by the Institutional Ethics Committee

\section{REFERENCES}

1. Jindal SK, Aggarwal AN, Gupta D, Agarwal R. Indian study on epidemiology of asthma, respiratory symptoms and chronic bronchitis in adults (in search). Int J Tubercul Lung Disea. 2012;16:1270-7.

2. Reilly JJ. Chronic obstructive pulmonary disease (COPD). Harrisons Principles of Internal Medicine, McGraw-Hill, New York; 2012:2151-60.

3. Mannino DM, Buist AS. Global burden of COPD: risk factors, prevalence, and future trends. Lanc. 2007;370(9589):765-73.

4. Rennard SI, Vestbo J. COPD: the dangerous underestimate of 15\%. Lancet. 2006;367:1216-9.

5. Global initiative for chronic obstructive lung disease (GOLD): Global strategy for the diagnosis, management, and prevention of chronic obstructive pulmonary disease; 2014. Available at: http://www.goldcopd.org/uploads/users/files/GOLD_ Report_2014_Jan23. pdf. Accessed on 20th June 2019.

6. Vijayan VK. Chronic obstructive pulmonary disease. Indian J Med Res. 2013;137:251-69.

7. Mathers CD, Loncar D. Projections of global mortality and burden of disease from 2002 to 2030 . LoS Med. 2006;3:e442.

8. Mannino DM, Buist AS. Global burden of COPD: risk factors, prevalence, and future trends. Lancet. 2007;370:765-73.

9. Burney P. The pharmacoepidemiology of COPD: Recent advances and methodological discussion. Europ J Respirat. 2003;22:1s-44s.

10. Rehman A, Hassali MA, Muhammad SA, Shakeel S, Chin OS, Ali IA, et al. Economic burden of chronic obstructive pulmonary disease patients in Malaysia: a longitudinal study. Pharmaco Economics-Open. 2020:1-0.

11. Drug utilization studies: methods and uses. Citation: Available at: https://apps.who.int/iris/ handle/10665/ 260517. Accessed on $12^{\text {th }}$ May 2020.
12. Faheemuddin MD, Ramaiah B, Kiran SS, Kumari BS, Vijayalaxmi M. Evaluation of Medication Adherence in COPD Patients and their Drug Utilization Pattern. I Med Pub. 2016;3:1-9.

13. Mohan A, Premanand R, Reddy LN, Rao MH, Sharma SK, Kamity R, et al. Clinical presentation and predictors of outcome in patients with severe acute exacerbation of chronic obstructive pulmonary disease requiring admission to intensive care unit. Bio Med Centr Pulm Med. 2006;6:27.

14. Hilleman DE, Dewan N, Malesker M, Friedman M. Pharmacoeconomic evaluation of COPD. Chest. 2000;118:1278-85.

15. McCrory DC, Brown CD. Anti-cholinergic bronchodilators versus beta2-sympathomimetic agents for acute exacerbations of chronic obstructive pulmonary disease. Cochrane Database Syst Rev. 2002;(4):CD003900.

16. Barr RG, Rowe BH, Camargo CA. Methylxanthines for exacerbations of chronic obstructive pulmonary disease. Coch Databa Syst Rev. 2003;2:CD002168.

17. Wood-Baker RR, Gibson PG, Hannay M, Walters $\mathrm{EH}$, Walters JA. Systemic corticosteroids for acute exacerbations of chronic obstructive pulmonary disease. Cochr Database Syst Rev. 2005;1:CD001288.

18. Ram FS, Rodriguez-Roisin R, Granados-Navarrete A, Garcia-Aymerich J, Barnes NC. Antibiotics for exacerbations of chronic obstructive pulmonary disease. Cochr Databa Syst Rev. 2006;2:CD004403.

19. Veettil SK, Rajiah K, Kumar S. Study of drug utilization pattern for acute exacerbation of chronic obstructive pulmonary disease in patients attending a Government Hospital in Kerala, India. J Family Med Prim Care. 2014;3(3):250-4.

20. Tashkin DP, Celli B, Senn S, Burkhart D, Kesten S, Menjoge S, et al. UPLIFT Study Investigators A 4year trial of tiotropium in chronic obstructive pulmonary disease. N Engl J Med. 2008;359:154354.

21. Miravitlles M, Murio C, Guerrero T, Gisbert R. DAFNE Study Group. Decisiones sobre Antibioticoterapia y Farmacoeconomía en la EPOC. Pharmacoeconomic evaluation of acute exacerbations of chronic bronchitis and COPD. Chest. 2002;121:1449-55.

Cite this article as: Salwan P, Singla J, Salwan S. Prescription pattern in the management of chronic obstructive pulmonary disease patients in a tertiary hospital: an observational study. Int J Basic Clin Pharmacol. 2020;9:1578-82. 